\title{
Differenz
}

Revista internacional de estudios heideggerianos y sus derivas contemporáneas

AÑO 8, NÚMERO 7: JULIO DE 2021. ISSN 2695-9011 - e-ISSN 2386-4877 - DOI: 10.12795/Differenz.2021.i07.04 [pp. 65-79]

Recibido: 05/06/2020

Aceptado: 30/06/2021

\section{¿Qué quiere decir leer? Interpretaciones en torno a légein, legen y lesen en camino a la pregunta por el decir del Habla en la obra de Martin Heidegger.}

\section{What does it mean to read? Interpretations of légein, legen and lesen on the way to the question of the saying of Speech in Martin Heidegger's work.}

\author{
Vanesa Gourhand \\ Universidad Nacional de Educación a Distancia
}

\section{Resumen:}

Pretendemos cuestionarnos en este breve estudio qué significa leer encaminándonos hacia la pregunta qué significa pensar. Ello en el contexto de la indagación hermenéutica por la modalidad del decir del Leer, implicada en la relación compleja entre leer, interpretar y comprender en la obra de Martin Heidegger. Para ello, en primer lugar, escucharemos los sentidos arcaicos del légein griego; seguiremos entonces el lugar de aquello que interpela o exhorta al pensar a pensar (como noeîn), un silencio que concierne al mortal en cuanto que lo dicho en el decir, su decir, no resulta a disposición de pensamiento representativo alguno, máxima indicación de la apertura a la alteridad que dicen los lenguajes. Finalmente marcaremos algunas conclusiones a modo de cierre del texto. 
Palabras clave: Escuchar/oír; decir; diálogo; colecta; leer; cobijo.

\title{
Abstract:
}

In this brief study, we try to question about what is called reading?, issue oriented towards the question what is called thinking?. This is in the context of hermeneutical inquiry into the way of Reading implicated in the complex relationship between reading, interpreting and understanding in Martin Heidegger's work. To do this, first of all, we are going to listen to the archaic senses of the Greek légein; then we will study the place of that which exhorts thinking itself to think (like noeîn), that is, a silence that concerns the mortal insofar as what is said in saying is not available to any representative thought, as a maximum indication of the openness to otherness that languages say. Finally, we would like to present some conclusions by way of closure.

Keywords: Listen/hear; tell; dialogue; collect; read; shelter.

\author{
HARNISCHSTRIEMEN,Faltenachsen, \\ Durchstich- \\ punkte: \\ dein Gelände. \\ An beiden Polen \\ der Kluftrose, lesbar: \\ dein geächtetes Wort \\ Nordwahr. Südhelln.
}

Paul Celan, Atemwende ${ }^{1}$

\begin{abstract}
Was heißt Lesen? Das Tragende und Leitende im Lesen ist die Sammlung. Worauf sammelt sie? Auf das Geschriebene, auf das in der Schrift Gesagte. Das eigentliche Lesen ist die Sammlung auf das, was ohne unser Wissen einst schon unser Wesen in den Anspruch genommen hat, mögen wir dabei ihm entsprechen oder versagen.

Ohne das eigentliche Lesen vermögen wir auch nicht das uns Anblickende zu sehen und das Erscheinende und Scheinende zu schauen.n.
\end{abstract}

Martin Heidegger, Was heist lesen $?^{2}$

1 "ESTRÍAS DE ESPEJO DE FALLA, ejes de pliegues,/puntos/de cizalla:/tu terreno.//En los dos polos/ de la rosa de fracturas, legible:/tu palabra proscrita./Norteverdadera. Surclara". CELAN, P. Obras completas. Tr. J. L. Reina Palazón. Trotta, Madrid, 2009, p. 213.

2 " ¿Qué significa leer? Lo que sustenta y dirige en el leer es la colecta. ¿En qué dirección colecta? En 


\section{Palabras iniciales}

El breve texto ¿Qué significa leer?, a penas un opúsculo marginal al final de la colección Aus der Erfahrung des Denkens (GA 13), nos demanda una verdadera experiencia de escucha a la palabra dicha a través de la estructura del lenguaje escrito. Iremos, por tanto, separando pensamiento a pensamiento, discerniendo y seleccionando, descubriendo, en lo posible, la cosa misma del pensar. Apelaremos a algunos de sus intérpretes para profundizar en la lectura del texto y esperemos que nos ayuden a recoger aquellas señas que indican el paso a lo que debería ser pensado o visto en lo dicho y lo no dicho en lo no pensado (el residuo ilegible), que sedimenta en todo proceso de escritura, y que todo Lector hábil deberá aprender a recoger. Son estas señas o condiciones del propio decir (mantener desoculto lo no-oculto) ${ }^{3}$, lo que intentaremos poner en relación con el texto de Martin Heidegger: ¿Qué significa leer?

\section{La colecta (Sammlung)}

Leemos e interpretamos el texto de Heidegger desde su traducción al castellano, aunque con la aportación de algunos términos en alemán o en griego cuando consideremos que estos son partícipes de la lectura en español, por considerar que desde la traducción ya estamos en la senda de la interpretación ${ }^{4}$ y que el leer es, también, traducir ${ }^{5}$. En esta doble

dirección a lo escrito, a lo dicho en el escrito. El leer propio es la colecta en dirección a aquello que, sin nuestro saber, ha reclamado ya nuestro esenciar, como quiera que en ello lo correspondamos o neguemos.

Sin el leer propio tampoco estamos en condiciones de ver lo que dirige nuestra mirada ni de apreciar lo que se manifiesta y aparece". HEIDEGGER, M. Aus der Erfahrung des Denkens (19101976). Klostermann, Frankfurt am Main, 1983, p. 111. ("¿Qué significa Leer?", en Experiencias del pensar (1910-1976). Tr. F. de Lara. Madrid, Abada, 2014, p.73.)

3 Un decir ontológico de raíz griega. "Tanto el $\lambda \varepsilon ́ \gamma \varepsilon I V$ como el vociv, cada uno desde su estructura, llevan a cabo lo que más tarde se llamará de propio y sólo por corto tiempo á $\lambda \eta \theta \varepsilon u ́ \varepsilon I v$ : desocultar y mantener desocultado lo develado". cfr. HEIDEGGER, M. ¿Qué significa pensar?. Tr. R. Gabas. Trotta, Madrid, 2008, p. 172.

4 "Y es que interpretar un texto no significa solo comprenderlo en sí mismo y desde su propio horizonte, ni tampoco, sin más, medirlo en la cuestión que trata con respecto a la verdad que sobre ella descubre y expresa, sino también, y articuladamente con ello, hacer que el texto nos hable a nosotros, a nuestra situación. En una palabra, hacerlo participar en un sentido presente. Es decir, la comprensión de un texto tiene el carácter de una application". NAVARRo CoRdón, J. M. "Leer e interpretar: algunas cuestiones relativas a la comprensión de textos". Studia Heidegeriana IX, 2020, p. 153.

5 Nos dice Gadamer: "El leer o el traducir parecen realizar la misma operación hermenéutica (...) la mera lectura de textos originales o traducidos es, en realidad, una interpretación por medio del sonido y del ritmo, de la modulación y de la articulación. Y todo ello se encuentra en la 'voz interior' y existe para el 'oído interior' del lector. La lectura y la interpretación vienen a ser 'interpretación'. 
dimensión nos dejamos guiar por las señas del decir deficiente y del decir exuberante ${ }^{6}$ y así forzarnos a comprender: "¿Qué significa leer? Lo que sustenta y dirige en el leer es la colecta"7.

La colecta (Sammlung). Para poner esta palabra en situación hemos de abrirnos y recoger otro texto del mismo autor titulado Logos (Heráclito, fragmento 5) ${ }^{8}$. En este texto Heidegger, presta atención a la sentencia de Heráclito que dice así traducida: "Si no me

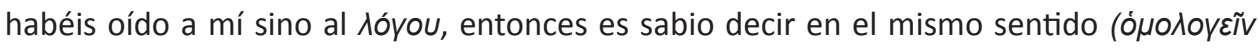

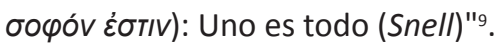

Heidegger vuelve sobre la cuestión del lógos $(\lambda o ́ y o \varsigma)^{10}$, porque considera que en ella Heráclito señala hacia un oír y decir ${ }^{11}$ en que se custodia "la cuestión del escuchar y decir" como la cosa misma del pensar. Continúa Heidegger: "Lo que es lógos lo sacamos del

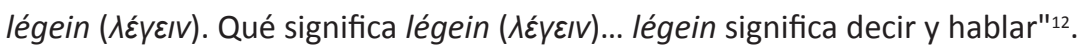

Ambas crean una nueva totalidad textual hecha de sonido y sentido. Ambas logran hacer una transposición que raya con lo creador. Se puede arriesgar la siguiente paradoja: cualquier lector es un medio traductor". GADAMER, H.-G. "Leer como traducir", en Arte y verdad de la palabra. Tr. J. F. Zúñiga García. Paidós, Barcelona, 2016, pp. 90-91.

6 "Esta doble condición del decir, tan extraña y antitética, aparece en dos principios de mi Axiomática para una nueva filología que suenan así: 1‥ Todo decir es deficiente -dice menos de lo que quiere; 2. Todo decir es exuberante -da a entender más de los que se propone". Cfr. NAVARRo Cordón, J. M. Op. cit. pp. 129-130.

7 El texto en alemán dice: "Was heißt Lesen? Das Tragende und Leitende im Lesen ist die Sammlung". HEIDEGGER, M. Aus der Erfahrung des Denkens (1910-1976). cit., p. 111.

8 HeIdegGer, M. "Logos (Heraklit, Fragment 50)". En Vorträge und Aufsätze (1936-1952). GA 7. Klostermann, Frankfurt am Main, 1989 (Ed. cast. Conferencias y artículos. Tr. E. Barjau. Serbal, Barcelona, 2001.

9 HeIDEGGER, M. Conferencias y artículos. Op. cit., p. 153. Los términos en griego son nuestros.

10 Citamos con variaciones la traducción al castellano de la traducción de Snell de la sentencia heraclítea con que se abre el texto Logos. Los términos en griego son nuestros. Heidegger retuerce la traducción del siguiente modo: "Perteneciendo no a mí sino a la posada que recoge y liga (aber der lesenden Lege gehörig): dejar estar-extendido Lo Mismo (Selbes liegen lassen): Io Bien Dispuesto (Geschickliches) esencia (west): Uno uniendo Todo". Ib., p. 167/s. 231. El Fragmento B 50 lo traduce

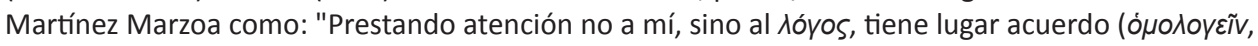

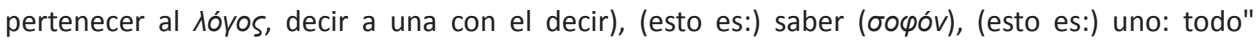
(MARtinez MARzoA, F. Historia de la filosofía. Istmo, Madrid, 1994, p. 29). El elemento especialmente problemático de la traducción de lógos viene, para Heidegger, al final de la sentencia. En orden de dejar de lado toda traducción "idealista" del Uno-unidad que bajo el esquema ontoteológico supusiera una suerte de Uno-todo (de todas las cosas), Heidegger ofrece a pensar el aforismo B 32 de Heráclito: "Lo uno, lo único sabio, no quiere y quiere ser llamado con el nombre de Zeus (DielsKranz)" HeIDEgGer, M. Conferencias y artículos. cit., pp. 163-165.

11 Volveremos más adelante sobre el oír.

12 HeIDEgGeR, M. Ib. p. 154. 12 Citando al profesor Marzoa "El griego hizo con el recoger y reunir discriminativo y caracterizante algo más grave que tomarlo para designar el 'leer'; echó mano de 
Continuando en el mismo pasaje, dos modos posibles se presentan para légein: Legen, poner algo (vorlegen) en el sentido de dejar tender o dejar yacer algo (vorliegenlassen), es decir, un llevar algo a que esté extendido o se presente como tal (poner una cosa junto a otra, com-poner) (zusammen-ins-Vorliegen-bringen), que puede ser leído como traer algo junto o reunido (Zusamentragen), y Lesen, leer ${ }^{13}$, como un juntar (Zusammenbringen), cosechar o re(coger), como la cosecha (lese) está presente o es recogida en la vendimia (Traubenlese) ${ }^{14}$. Hemos de anticipar que ninguno de estos sentidos, tampoco su articulación abierta, puede apuntar a un mero amontonar o acumular (als bloßes Anhäufen) -especialmente en lo que toca a los significados de palabras griegas- que redujera lo cualitativamente diferencial de la cosa (recogida, recolectada, dicha) en el decir $^{15}$.

Vamos notando, pues, cómo, por un lado, Heidegger nos dice que la palabra Légein ${ }^{16}$ significa "decir y hablar", como han traducido habitualmente las tradiciones filológicas y filosóficas a lo largo de los últimos siglos, distanciandolo de sus imposibles traducciones por ratio o Vernunft. Pues tiene légein un significado anterior que es: poner abajo y poner delante (nieder- und vorlegen), un poner una cosa junto a otra (Zusammenbringen). Este "poner", aparentemente sin agente de su acción, no coloca o sitúa la cosa (stellen), sino que supone un dejar-puesto-delante-junto (beisammen-vor-liegen-lassen) (desde sí mismo, por sí mismo) que reúne; y, lo más importante, es un poner como dejar en cobijo

él para la nada inocente empresa de decir el decir. Y, al echar mano precisamente de ese verbo, el griego interpreta que reunir discriminativamente, por lo tanto contar y separar, deja a cada cosa su lugar y así juntar unas cosas con otras y separarlas de otras, eso es el decir". MARTínez MARzoA, F. De Grecia y la Filosofía. Universidad de Murcia, Murcia, 1990, p. 101.

13 Leer nos viene del latín lěgere de raíz indoeuropea: "*leg: Recoger, colectar (y derivados que significan hablar). Lat. legõ: recoger, escoger, leer". ROBERTS, E. \& PASTOR, B. Diccionario etimológico indoeuropeo de la lengua española. Alianza, Madrid, 2019.

14 HeIDEgGer, M. "Logos (Heraklit, Fragment 50)". cit., pp. 214-215.

15 El profesor Martínez Marzoa ha diferenciado los usos propiamente homéricos del légein (recoger o reunir según alguna norma o ley: seleccionar(-discernir)-albergar-recoger) de aquellos significados que Heidegger asume en légein, también con Homero, y que habitualmente los diccionarios referencian a otros verbos. Hablamos de los significados de los verbos legen y liegen en alemán. Así, si legen dice legen lassen, légein se traduciría por vorliegen lassen, dejar-yacer-ya (con carácter previo, no-óntico) aquello que es o dejar-yacer-delante, como la traducción al castellano suele subrayar. Interpretamos que con ello, Heidegger marcaría el carácter ontológico del légein, valdría decir, del decir mismo, en cuanto dejar yacer o estar o ser las cosas en cuanto cosas dichas en el decir. MARtínez MARzoA, F. De Grecia y la Filosofía. cit., pp. 65-67.

16 HeIdegGer, M. "Logos (Heraklit, Fragment 50)". cit., ss. 216-217; pp. 154-155. 
(in der Hut zu lassen) o albergar (bergen) en el desocultamiento (Unverborgenheit), de tal modo que la cosa así albergada (geborgen) permanece puesta en custodia ${ }^{17}$.

Si prestamos atención al "juego" de palabras con todas sus posibilidades semánticas, podemos oír que en el alemán de Heidegger el albergar, el cobijar, el guardar, co-suenan respondiendo a la estructura esencial de la recolección (Lese) ${ }^{18}$. Pues, como ya hemos dicho, el leer es una colecta o recolección (Lese) donde tiene acogida y lugar, posada (Lege), el reunir, juntar y recoger que significa originariamente el légein del lógos (la acción de $\log _{0}{ }^{19}$ o la puesta en obra de lo Dicho).

En este sentido la recolección (colecta) está llevada, portada, por el albergar ${ }^{20}$, que -diciendo guardar, cuidar, cobijar- acoge el fruto donado por la tierra. El albergue (Entbergung, lo que entraña abrigo) es lo fundamental, lo que pone en movimiento y guía la recolección.

Ahora bien, el recoger, que empieza propiamente desde el albergar, es de antemano un elegir ${ }^{21}$. La selección ${ }^{22}$ está determinada por aquello que dentro de lo elegible (e-legible, posible para un leer en cuanto colecta) se da como lo selecto o digno de selección, lo mejor (aquello cuya presencia, estatuto ontológico, es por sí mismo estando a la espera de ser recogido). Notamos cómo en la estructura esencial de la recolección (legere), lo primero que hay ante (el) albergar es la "selección"; el légein es una acción que tiene carácter discriminatorio, selectivo, determinante ${ }^{23}$, en lo que toca a un segundo sentido también. En el reunir está el hecho de que los que recogen se reúnan del mismo modo, el

17 En torno a los sentidos arcaicos del légein griego, cfr. MARtínez MARZOA, F. De Grecia y la Filosofía. cit., pp. 61-67.

18 HeIDEgGer, M. "Logos (Heraklit, Fragment 50)". cit., s. 215.

19 Aquí logos entendido como mito. V. Martinez MARzoA, F. Historia de la filosofía. cit., p. 22; GadAmer, H.-G. Mito y Razón, Tr. J. F. Zuñiga García. Paidos, Barcelona, Paidos, 2010, pp. 67-133.

20 Cobijar (en lengua castellana): dar refugio, guarnecer a alguien, amparar dandole protección, contener, cubrir. También, guardar, acoger, mantener (cuidar lo aprendido, preservar del olvido).

21 Podríamos cifrar el carácter selectivo (previo) del albergue que supone el decir, como e-legir. Se juega en esta expresión con el guión menor para denotar la condición de ligazón que está velado en el elegir.

22 La se-lección: lección es recogido en lesen (leer). Continuo en el juego de desambiguación que se nos permite en lengua castellana entre: selección, elección, lección, elegir-ligar. Ello para poner en relevancia la condición de lo reunido (legos) que empieza propiamente a partir del albergar, la recolección que es, en sí misma, de antemano, un elegir (e-legir) aquello que pide albergue. Pero la selección (se-lección (hay envío/hacía)), por su parte, está determinada por aquello que dentro de lo elegible (e-legible -se deja leer) se muestra como lo selecto (lo mejor). En la estructura esencial de la recolección, lo primero que hay frente al albergar es el elegir. V. NAVARRo Cordón, J. M. Op. cit., pp. 148-152.

23 Cfr. Martinez MarzoA, F. Historia de la filosofía. cit., p. 9. 
hecho de que coliguen su hacer en vistas del albergar y de que, una vez reunidos, reúnan. La recolección pide desde sí estos dos sentidos de "reunión"24, un reunir discerniente y discriminatorio, ni exclusivo ni inclusivo, con el que se reconoce a cada cosa su lugar, un poner como dejar-ser cada cosa en su ser propio ${ }^{25}$.

Volvamos a nuestro hilo. Al légein ${ }^{26}$ como "poner" le importa únicamente dejar ${ }^{27}$ en cobijo (un cobijo bajo el cual permanece puesta la cosa siendo aquello que se es por sí mismo, desde sí mismo). Esto es, decir y hablar "esencian" -son y dejan ser aquello que son por sí mismo- como este singular poner (dicho cómo ex-poner, des-cubrir, desplegar) aquello que está o se hace presente, en un desocultamiento. El hablar que piensa Heidegger, en cuanto hablar que esencia como Legen $^{28}$ y Lesen, no se determina por tanto ni desde la emisión sonora ni desde la apertura de la significación semántica. Más bien el hablar del lenguaje (de la verdad del ser) acaece desde el desocultamiento de

24 HeidegGeR, M. "Logos (Heraklit, Fragment 50)". cit., ss, 174-175; pp. 158-159.

25 Cfr. Martinez MarzoA, F. Historia de la filosofía. cit., p. 10.

26 "Empecemos por decir finalmente qué significa 'decir'. Pensemos finalmente por qué y en qué

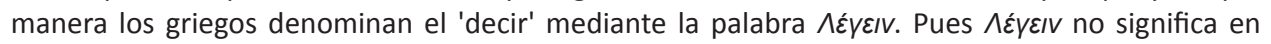
ninguna manera 'hablar'. La significación de $\Lambda \dot{\gamma} \gamma \varepsilon I V$ no está referida necesariamente al lenguaje y al acontecer del mismo. El verbo $\Lambda \dot{\gamma} \gamma \varepsilon I V$ es la misma palabra que el latín legere y que el alemán legen. Cuando alguien hace (o pone delante) una propuesta, con ello no entendemos que él traslada el papel a la mesa, sino que comenta la propuesta. Cuando alguien comenta un suceso, esto es un exponer. Si pensamos una cosa a vueltas con nosotros mismos, la reflexionamos, es decir, la ponemos (o doblamos) sobre ella misma (en alemán, überlegen). Poner delante, exponer, reflexionar todo eso que guarda relación con la palabra (poner), equivale al griego $\Lambda \varepsilon ́ \gamma \varepsilon / v$. Esta palabra nunca significa para los griegos, como si saliera de la pura nada, algo así como 'decir'; más bien, a la inversa, los griegos entienden el decir desde el poner delante, el exponer, el reflexionar, $y$

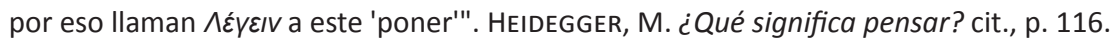

27 Dejar (en lengua castellana): liberar, ceder, retirarse-para, dejar venir, permitir o dar paso para que algo se de como algo. Nombrar, designar. Abandonar. Encomendar. Ausentarse. Dar/soltar. Desapropiarse.

28 "Si colocamos y ponemos delante algo, hacemos que yazca, y entonces en un ser yacente ante nosotros. Pero algo puede yacer ante nosotros sin que seamos nosotros los que hayamos llegado a ponerlo. Yacen ante nosotros el mar, las montañas. Yacer en griego equivale a $\kappa \varepsilon i ́ \sigma \Theta a$. Lo subyacente

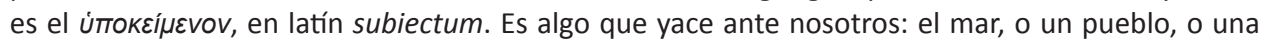
casa, o cosas parecidas. Sólo una mínima parte de lo que así yace ante nosotros la ha puesto el hombre en la situación en la que está, y esa mínima parte la ha puesto solamente con ayuda de lo que subyacía ya ante él. Las piedras de los muros de una casa proceden de una roca que ya sea había formado (...); lo que se ha puesto, lo que se ha asentado y así yace ante nosotros (...) lo puesto significa siempre lo que ha llegado a yacer y, por tanto, lo yacente. Lo puesto es lo dejado libre en su puesto, no lo producido por nuestra acción y, en ese sentido, dependiente de nosotros". HEIDEGGER, M. ¿Qué significa pensar? cit., pp.167-168. 
lo presente ${ }^{29}$. Por ello alétheia tiene que ver con légein y lógos es expresado como Vorliegen-lassen (dejar-estar-junto-delante).

Retomemos, ahora sí, al pensamiento que nos llevó al texto Logos.

\section{La escucha}

¿Qué significa leer? Lo que sustenta y dirige en el leer es la colecta: Leer esencia en la colecta, es decir, en el recoger o recolectar (en la e-lección de lo e-legible por el leer). Si bien: "¿En qué dirección colecta? En dirección a lo escrito, a lo dicho en el escrito"30.

Ya hemos anotado la importancia que tiene en la "colecta" (Sammlung) el albergar o cobijo que custodia y congrega: la colecta es colecta por la selección y el dejar-a-cubierto. Ahora, se nos señala que aquello que guía (en dirección a) la custodia y la selección es la obra y lo allí escrito, lo dicho en el escrito, es decir, lo que orienta la lectura es lo puesto en $o b r a^{31}$ en el decir (legen -"lo yacente o lo dejado libre en su puesto") de lo dicho. Lo dicho en el escrito nos interpela, nos motiva o exhorta desde su decir selecto (cuando ello se da). Así nos lo sugiere el profesor Navarro Cordón:

Leer un texto es un procedimiento de comunicación entre el texto y nosotros mismos en relación con la cosa referida por aquel y que incoa nuestra pregunta e interpelación. El texto ha surgido como respuesta a una pregunta o cuestión ante la que se encontró el pensador, de modo que el texto como lo expresamente dicho adquiere sentido desde esa latencia problemática y como desarrollo de esa cuestión y pregunta (...) la intelección del texto exige hacerse cargo y comprender esa pregunta, reconducirlo todo él a ella y reconstruir desde ella su sentido ${ }^{32}$.

Ahora bien, habíamos señalado que Heidegger vuelve sobre la cuestión del lógos, porque considera que en ella Heráclito señala hacia un oír y decir en que se custodia

29 En torno a la verdad ontológica o del ser que retiene la noción heideggeriana de alétheia propiamente en el poema de la diosa-alétheia, v. DíAz ARROYO, J. L. "Anotaciones a la cuestión de la verdad en el poema de Parménides a propósito de la diosa-alétheia", en Grecia y nosotros. Hermenéutica y lenguajes poéticos. Dykinson, Madrid, 2021.

30 "Worauf sammelt sie? Auf das Geschriebene, auf das in der Schrift Gesagte". HeIDEGGER, M. Aus der Erfahrung des Denkens (1910-1976). cit., s. 111; p.73.

31 V. HeIDEgGer, M. "El origen de la obra de arte". en Caminos del Bosque. Tr. H. Cortés y A. Leyte. Alianza, Madrid, 2003; OÑATE, T. "Heidegger hó skoteinós (el obscuro): la ontología estética del espacio tiempo tras la Kehre del Segundo Heidegger", en Estética Ecología y Filosofía de la Historia (Hermenéuticas contra la violencia III). Madrid, Dykinson, 2019.

32 Navarro Cordón, J. M. Op. cit., pp. 145-146. 
"la cuestión del escuchar y decir" como la cosa misma del pensar. En esta "falla", quizás podamos comprender el "y" que reúne el oír y decir, la pregunta que surge es ċacaso lo dicho en lo escrito, aquello que nos interpela y guía, no es necesario que sea oído para poder ser leído?

Heidegger nos dice que "lo que está-delante que, reunido, ha sido extendido delante, es algo determinado que nos exhorta a la escucha atenta y cuidadosa. El oír es propiamente este concentrarse que se recoge para la interpelación y la exhortación y que, así, reconoce el carácter del otro como otro (por sí mismo). El oír es en primer lugar la escucha concentrada"33. Decir "y" oír ${ }^{34}$ : Para el leer es necesaria una escucha concentrada que encamina a lo legado en el texto, hay que poder oír lo que dice lo escrito para poder comprender ${ }^{35}$, para que haya diálogo. Y aun así, lo más importante que nos señala Heidegger, lo aún por ser pensado, es que decir y oír tienen que ser del mismo origen, del origen esenciante del mismo lenguaje, que aquí tentativamente llamamos el lenguaje del Ser (Seyn).

33 "¿Qué es el oír? Como $\Lambda \varepsilon ́ \gamma \varepsilon I V$, el hablar no se determina desde el sonido que expresa sentido. De este modo, si el decir no está determinado desde la emisión de sonidos, entonces el oír que le corresponde no consiste en primer lugar en que un sonido que alcanza al oído sea captado (...) Si nuestro oír fuera ante todo una captación y transmisión de sonidos, y no fuera más que esto (...) entonces lo que ocurriría sería que lo sonoro entraría por un oído y saldría por el otro. Esto es lo que de hecho ocurre cuando no nos concentramos a escuchar lo que se nos dice. Pero lo que se nos dice es lo que está-delante que, reunido, ha sido extendido delante, es algo determinado que nos exhorta a la escucha atenta y cuidadosa. El oír es propiamente este concentrarse que se recoge para la interpelación y la exhortación y que, así, reconoce el carácter del otro como otro (por sí mismo). El oír es en primer lugar la escucha concentrada. HeIDEGGER, M. "Logos (Heraklit, Fragment 50)". cit., s. 174; p. 158.

34 "Todo decir tiene que hacer surgir conjuntamente el poder oír. Ambos tienen que ser del mismo origen. Entonces rige sólo una cosa: decir el más noble lenguaje surgido en su simplicidad y fuerza esencial, el lenguaje del ente como lenguaje del ser (Seyn). Esta transformación del lenguaje penetra en ámbitos que todavía nos están cerrados, porque no sabemos la verdad del ser (Seyn). Entonces se habla de la "renuncia del seguimiento", del "claro de la ocultación", del "evento-apropiador", del "ser-ahí", no un entresacar verdades de las palabras, sino la inauguración de la verdad del ser (Seyn) en tal decir transformado. Heidegger, M. Aportes a la filosofía: Acerca del evento. Tr. D. V. Picotti. Biblos, Buenos Aires, 2006, p.77.

35 "Cuando hablamos del oír y el ver en relación con el leer, no se trata de que haya que ver para poder descifrar lo escrito, sino que lo que importa es que hay que oír lo que dice lo escrito. Tener la capacidad de oír es tener la capacidad de comprender".GADAMER, H.-G. Mito y Razón. cit., pp. 70-71. 


\section{Noeîn}

Continuamos leyendo a Heidegger: "El leer propio es la colecta en dirección a aquello que, sin nuestro saber, ha reclamado ya nuestro esenciar, como quiera que en ello lo correspondamos o neguemos" ${ }^{16}$.

En toda lectura hay un recogimiento que tiene lugar cuando correspondamos al oír de lo dicho en lo escrito, pertenecemos a su decir o un emplazarse en él. En el encuentro con la obra (alcanzar algo en la andanza de un camino) ${ }^{37}$, cuando se da, hacemos una experiencia del habla con el $\mathrm{Habla}^{38}$. Con ello queremos decir, aquello que nos mueve a tomar en consideración (vocív) y nos interpela, remite en sí mismo a aquello que nos afecta $^{39}$ (el habla del Habla), ya que "sin el leer propio tampoco estamos en condiciones de ver lo que dirige nuestra mirada ni de apreciar lo que se manifiesta y aparece ${ }^{140}$.

El leer propio (yacer dispuesto o estar desvelado ${ }^{41}$ ), opinamos aquí que pone en juego la guarda de la memoria (dialecto ${ }^{42}$ ), en el sentido de lo más propio -lo ignorado en su misterio irreductible- que nos tiene y mantiene ex-puestos ${ }^{43}$. Nos dirigimos al texto desde nuestra propia lengua y desde ella nos ex-ponemos a su juego: a recrear y crear lo aún no pensado en lo Dicho. El leer es un decir-oír-en-diálogo: encuentro atento, pero, también discernimiento, diferenciación (alteración) en vista o dirigido a la comprensión de eso dado o donado en la e-lección, aquí como advenimiento.

36 "Das eigentliche Lesen ist die Sammlung auf das, was ohne unser Wissen einst schon unser Wesen in den Anspruch genommen hat, mögen wir dabei ihm entsprechen oder versagen". HEIDEGGER, M. Aus der Erfahrung des Denkens (1910-1976). cit., s. 111; p.73.

37 V. Heidegger, M. "La esencia del habla". En De camino al habla. Tr. I. Zimmermann. Serbal, Barcelona, 2002, p.126.

38 "Hacer una experiencia con algo -sea una cosa, un ser humano, un dios- significa que algo nos acece, nos alcanza; que se apodera de nosotros, que nos tumba y nos transforma (... ) Algo se hace, adviene, tiene lugar". Ib. p. 119.

39 cfr. HeIDEGGER, M. ¿Qué significa pensar? cit., p. 173.

40 "Ohne das eigentliche Lesen vermögen wir auch nicht das uns Anblickende zu sehen und das Erscheinende und Scheinende zu schauen". HEIDEGGER, M. Aus der Erfahrung des Denkens (19101976). cit., s. 111; p.73.

41 V. Duque, F. "El Dios del otro inicio". Endoxa: Series filosóficas 20, 2005, pp. 722.

42 V. HEIDEgGER, M. "Lenguaje y tierra natal". En Experiencias del pensar (1910-1976). cit.

43 " El ser (Seyn) necesita del hombre para esenciarse, y el hombre pertenece al ser (Seyn), para realizar su extrema determinación como ser-ahí (...) Esta contraposición entre el necesitar y el pertenecer constituye al ser (Seyn) como evento y lo primero que pensantemene nos incumbe es elevar la simplicidad del saber y fundar en su verdad la oscilación de esta contraposición". Cfr. Heidegger, M. Aportes a la filosofía: Acerca del evento. cit., p. 207. 


\section{La cuestión del pensar}

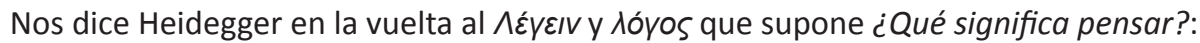

I) El dejar que yazca (decir) y el tomar en consideración (Noeîn) es pensar.

II) La acción misma de decir traza y desbroza el camino del pensar.

III) El pensar percibe de antemano ${ }^{44}$ de tal manera que toma en consideración.

A tenor de lo cual el pensar-decir, sus articulaciones, se tornan en cuestión. Al respecto, qué es tomar en consideración (in-der-Acht-nehmen, traducción tardía del noeîn del poema de Parménides) si no, acaso, el permanecer atentos a la escucha del decir de la Palabra.

Decíamos que en el leer, como colecta, hay un acogimiento que recoge: el recogimiento de la ofrenda o don (dejar yacer). Por tanto, en el recogimiento como leer propio -desvelar ${ }^{45}$ - y como decir (Légein) propio -dejar a cobijo-, se da un pensar que reúne y custodia lo recolectado pero que no anula las diferencias entre el decir (la cosa del decir) y lo que obra en lo Dicho (lo que asienta verdad ${ }^{46}$ ). Parecería, que leer, como colecta, es un escuchar (en el oído despierto) en vista -tener el ojo para el "ser"47- al acontecer de la puesta en obra del decir del Seyn ${ }^{48}$.

De Legein descubrimos lesen (escoger-recoger) y legen (poner-tender). Legen es en tanto acción poner una cosa junto a otra cosa, com-poner y, así, tender (com-pasar), un

44 "En expresiones antiguas la palabra presentir se usa en forma impersonal: se presiente, o incluso algo me dice: algo me sobreviene, me estremece. El auténtico presentir es la forma por que nos llega algo esencial y se ofrece a nuestra consideración, para que la mantengamos en ella. Ese presentir no es un escalón previo en la escalera del saber. Es el pórtico que esclarece todo lo que puede saberse, es decir, lo esconde (custodia)". HeIDEGGER, M. ¿QQué significa pensar? cit., p. 230.

45 V. DUQue, F. Op. cit. p. 723.

46 Cfr. " Sage (el Dicho): es la esquiva y en el fondo inefable raíz de sagen: decir (...) sería como hallar la Palabra (Verbum, lógos) en la estuviera concentrado en la que a su vez se expeliera o destinara todo el lenguaje, toda expresión, lectura y dicción". DUQUE, F. nota. HEIDEGGER, M. Desde la experiencia del pensar. Tr. F. Duque. Abada, Madrid, 2013, p. 52.

47 Cfr. Heidegger, M. El Evento. Tr. D. V. Piccoti. El hilo de Ariadna, Buenos Aires, 2016, p. 31.

$48 \mathrm{El}$ ser (Seyn) acaece (ex-pone) al ser-ahí (instante-sitio) y tan solo de este modo se esencia (funda) como evento: "El evento es la palabra inicial porque su adjudicación (como la única a-propiación de la esencia humana en la verdad del Seyn dispone la esencia del hombre sobre la verdad del Seyn (...) como evento la disposición acaece, el acaeciente comienzo (es decir, el Seyn abísmate en su verdad) es la voz inicialmente comienzo. La voz dispone en tanto apropia la esencia del hombre a la verdad del Seyn (...) Acaeciente, la 'disposición' no es un estado sentimental del hombre, sino el evento de la palabra como apropiación que se adjudica. La palabra es en su esencia acaeciente silenciosa". Ib. p. 219. 
llevar algo desde lo oculto -dejar-lo ser- hacia el estado de desocultamiento (lo que se presenta ha salido de su desocultamiento) ${ }^{49}$.

¿Y Lesen (Lĕgere)? es, en tanto acción, escoger y recoger. La recolección es en vista al albergar, dejar en cobijo (estancia) al abrigo desde el cual permanecer -un permanecer nada plano, un presentarse en lucha con la ausencia- dispuestos al son silente del habla.

Legen y Lesen se despliegan como modos de dar-se diferenciales del hablar del Habla, siendo el lenguaje la unidad-mismidad (lo mismo, lo que se pertenece recíprocamente ${ }^{50}$ ) desde la que hace surgir la copertencia (Zusammengehören) de ser y pensar ${ }^{51}$.

El lenguaje habla (ex-pone) al leer (lesen), como acción diferenciante ${ }^{52}$, la palabraofrenda que debe ser recogida ${ }^{53}$. Lo más propio del habla se dice desde la escucha atenta del pensar (o tomar en consideración) (al) ser del ente, a la presencia de lo presente, aquello que llama al pensamiento (Lógos) que permanece cobijado en la textura de la obra donde la Palabra-seña ${ }^{54}$ tiene lugar para resonar y ser oída, la seña indica el paso

49 cfr. HeIDEGGER, M. ¿Qué significa pensar? cit., p. 194.

50 lb. p. 199.

51 Copertenencia es el modo en que Heidegger nos ofrece a pensar el "lo mismo" del poema de Parménides, "palabra enigma" cuyas interpretaciones han marcado el devenir de la historia de Occidente, al menos la filosófica (En HeIDEgGeR, M. Conferencias y artículos. cit., pp. 171-175); se nos exige pensar una interpretación de aquella "relación" (pensar "y" ser) que no reduzca ser a objeto, ni tan siquiera a cosa, del mismo modo que pensar nada tendría que ver con un pensamiento representativo. En torno a la relación de lo mismo y la diferencia, v. especialmente los textos de Identität und Differenz (GA 11).

52 "El pensar, en cuanto habérselas con las cosas y el ser, es discernimiento que, como tal, comporta intervalos, cortes $y$, en definitiva, encierra el cuestionamiento en torno al por dónde cortar, cuestionamiento por el criterio del desde dónde, hacia dónde o por dónde se daría la diferencia misma entre el ser y lo ente (así como las propias delimitaciones de lo ente). Por ser discernimiento el pensar corresponde al ser, así como tiene lugar en el decir". Cfr. Díaz Arroyo, J. L. "Del Sí mismo a lo mismo: comentarios a los lugares de la mismidad del Poema de Parménides de Elea en el camino de Martin Heidegger hacia los 'pensadores del inicio'". Human review. International humanities review (Aprobado para su publicación, estimada 2021).

53 "En tal esenciarse de la seña el mismo ser (Seyn) llega a su madurez. Madurez es disposición de tornarse un fruto y una donación. Aquí se esencia lo último, el fin esencial, exigido desde el comienzo, a él no aportado. Aquí se descubre la más íntima finitud del ser (Seyn): en la seña del último dios.

En la madurez, en la potencia para el fruto y en la grandeza de la donación se encuentra a la vez la más oculta esencia del no, como todavía-no y no-más". v. Heidegger, M. Aportes a la filosofía: Acerca del evento. cit, p. 329.

54 "LA PALABRA: Nada, en ningún lugar, nunca,/antes de todo algo, antes del entonces y el ahí,/ se alza la palabra/del abismo que concede/lo que ningún fundamento/alcanza,/pues sólo la alianza/con lo dicho/hace de la cosa, cosa/sólo ella captura de nuevo/los sentidos perseguidos,/ confusamente desplazados,/en un sentido/que ya no sobresale/en dirección alguna". HeIDEGGER, M. Experiencias del pensar (1910-1976). cit., p. 31. 
a lo que debería ser pensado y visto. En la interpretación hay habla (diálogo) si se da la apertura de sentido que com-padece, es decir, dejar ser al otro en su alteridad (lo otro de mí mismo y lo otro como sí mismo) dando lugar a la diferencia intransitiva-necesaria de la co-ligación (Versammlung) (juntar-unir quizás un modo de decir participar) y la reunión (la unión desde el deseo- armonía) desde la alteridad de la palabra alzada: ESTRÍAS DE ESPEJO DE FALLA -la imagen poética (ensambladura) denota como seña ${ }^{55}$.

El Leer es un modo privilegiado del habitar poéticamente el hombre.

\section{Recogimiento}

\section{¿Qué quiere decir Leer?}

Leer quiere decir Diálogo, como ese encaminarse por el camino trazado por el habla para que el lector y lo puesto en obra puedan oírse y decirse y, así, descubrir el espacio en el que pueda acontecer el sentido de la unidad de obra ${ }^{56}$. El diálogo como una apertura a lo ya sido, a lo que todavía-no y a lo que es: aquí es donde nos encontramos interpelados.

Leer quiere Decir, deseo de Ilevar-a-que-(algo) esté-junto-extendido-delante, discerniendo y diferenciando a la vez que recogemos lo ofrendado, un atender lo que dice el texto: "prestar oído a lo que a uno le es concedido" nos dice Heidegger, darle valor a lo dicho (consideración), recoger lo más selecto, lo que pide albergamiento, demorarse y dejarse conducir por lo ya pensado, dejarnos decir y afectar por ello y por lo que permanece velado.

Leer quiere decir Interpretar, la interpretación nos expone, es un encuentro en la encrucijada de un cruce de caminos, límite que reúne y separa y en el que se abre un espacio donde acaece una apropiación ${ }^{57}$. Es un espacio de discernimiento (decidir, separar, distinguiendo lo uno de lo otro como lo uno y lo otro). Un encontrarse en donde nos dejamos estar, tocar y decir por el querer de lo puesto en obra y nos dejamos penetrar por la palabra que necesita ser escuchada. Aunque, se trate de un encuentro que repliega

55 V. CóRdobA OsPINA, G. "Meditación, Imagen (pensar y poetizar)" en Confrontación en la imagen: Un tránsito hacia el pensar del otro inicio de Martin Heidegger. Cuadernos de Studia Heideggeriana: Studia Heideggeriana. Madrid, 2021, pp. 115- 205.

56 V. OÑATE, T. Para leer la metafisica de Aristoteles en el siglo XXI: Análisis Críticohermenéutico de los catorce lógoi de Filosofía primera. Dykinson, Madrid, 2001, pp. 560-655

57 Cfr. Navarro Cordón. J. M. Op. cit., p. 150 
pues allí impera un emplazarse en el movimiento del habla, una cierta harmonía disimétrica que nos envuelve, en cada puesta en acción ${ }^{58}$ del obrar del sentido del texto.

¿Y la colecta? La colecta es la que recoge la donación: En la madurez, en la potencia para el fruto. Y lo recoge como Lógos, en su ambigüedad o doblez como aquello que reúne y como palabra. Aquel que se pone a prueba en el espacio de juego del lenguaje, aquel que baja la guardia, que abandona la vigilia, aquel dispuesto a hacer la experiencia misma del olvido ${ }^{59}$. Son estos ${ }^{60}$ los que leen (oír en vista) la voz silente del lenguaje del ser en obra-ofrenda: Abismosamente fundado en el evento está el ser-ahí y con ello el hombre, cuando logra el salto en fundación creadora ${ }^{61}$.

Leer es escuchar el decir del habla en los márgenes del silencio.

\section{Bibliografía.}

CelAN, P. Obras completas. Tr. J. L. Reina Palazón. Trotta, Madrid, 2009.

CóRdobA OSPINA, G. "Meditación, Imagen (pensar y poetizar)" en Confrontación en la imagen: Un tránsito hacia el pensar del otro inicio de Martin Heidegger. Cuadernos de Studia Heideggeriana: Studia Heideggeriana. Madrid, 2021, pp. 115- 205.

Díaz Arroyo, J. L. "Anotaciones a la cuestión de la verdad en el poema de Parménides a propósito de la diosa-alétheia", en Grecia y nosotros. Hermenéutica y lenguajes poéticos. Dykinson, Madrid, 2021.

Díaz Arroyo, J. L. "Del Sí mismo a lo mismo: comentarios a los lugares de la mismidad del Poema de Parménides de Elea en el camino de Martin Heidegger hacia los 'pensadores del inicio'". Human review. International humanities review (Aprobado para su publicación, estimada 2021).

DUQUE, F. "El Dios del otro inicio". Endoxa: Series filosóficas 20, 2005, pp. 719-732.

Gadamer, H.-G. Arte y verdad de la palabra. Tr. J. F. Zúñiga García. Paidós, Barcelona, 2016.

Gadamer, H.-G. Mito y Razón, Tr. J. F. Zuñiga García. Paidos, Barcelona, Paidos, 2010.

58 En torno a la necesidad del carácter activo del desplegarse de la verdad del ser como alétheia en Heidegger, siguiendo a sus fuentes griegas, especialmente Aristóteles, v. Oñate, T. "Heidegger hó skoteinós...". cit.

59 Duque, F. nota 40. HeidegGer, M. Desde la experiencia del pensar. cit.

60 V. Heidegger, M. "La esencia del habla". cit. pp. 125-127

61 V. Heidegger, M. Aportes a la filosofía: Acerca del evento. cit, p. 229. 
Heidegger, M. Aus der Erfahrung des Denkens (1910-1976). GA 13. Hg. H. Heidegger. Klostermann, Frankfurt am Main, 1983 (Experiencias del pensar (1910-1976). Tr. F. de Lara. Madrid, Abada, 2014).

HeIDEGGer, M. "Logos (Heraklit, Fragment 50)". Vorträge und Aufsätze (1936-1952). GA 7. Hg. F.-W- von Hermann, Klostermann, Frankfurt am Main, 1989 ("Lógos (Heráclito, Fragmento 50)". Conferencias y artículos. Tr. E. Barjau. Serbal, Barcelona, 2001).

Heidegger, M. "La esencia del habla". En De camino al habla. Tr. I. Zimmermann. Serbal, Barcelona, 2002.

Heidegger, M. "El origen de la obra de arte". en Caminos del Bosque. Tr. H. Cortés y A. Leyte. Alianza, Madrid, 2003.

Heidegger, M. Aportes a la filosofía: Acerca del evento. Tr. D. V. Picotti. Biblos, Buenos Aires, 2006.

HeIdegGeR, M. ¿Qué significa pensar?. Tr. R. Gabas. Trotta, Madrid, 2008.

HeIDEgGeR, M. Desde la experiencia del pensar. Ed. bilingüe a cargo de F. Duque. Abada, Madrid, 2013.

Heidegger, M. El Evento. Tr. D. V. Piccoti. El hilo de Ariadna, Buenos Aires, 2016,

Martínez MarzoA, F. De Grecia y la Filosofía. Universidad de Murcia, Murcia, 1990

Martinez MarzoA, F. Historia de la filosofía. Istmo, Madrid, 1994

NAVARRo Cordón, J. M. "Leer e interpretar: algunas cuestiones relativas a la comprensión de textos" en Francois Jaran (eds.) Studia Heidegeriana IX (Ed. F. Jaran). 2020.

Oñate, T. Para leer la metafisica de Aristoteles en el siglo XXI: Análisis Críticohermenéutico de los catorce lógoi de Filosofía primera. Dykinson, Madrid, 2001.

OÑATE, T. "Heidegger hó skoteinós (el obscuro): la ontología estética del espacio tiempo tras la Kehre del Segundo Heidegger", en Estética Ecología y Filosofía de la Historia (Hermenéuticas contra la violencia III). Madrid, Dykinson, 2019.

ROBERTS, E. \& PASTOR, B. Diccionario etimológico indoeuropeo de la lengua española. Alianza, Madrid, 2019. 